\title{
Do differences exist between chronic hepatitis C genotypes 2 and 3 ?
}

\author{
Isaura Cunha Melo ${ }^{[1]}$, Maria Lucia Gomes Ferraz ${ }^{[1]}$, Renata Mello Perez ${ }^{[2]}$, \\ Christine Takemi Emori ${ }^{[1]}$, Silvia Naomi de Oliveira Uehara ${ }^{[1]}$, \\ Roberto José de Carvalho-Filho ${ }^{[1]}$, Antonio Eduardo Benedito Silva ${ }^{[1]}$ \\ and Ivonete Sandra de Souza e Silva ${ }^{[1]}$
}

[1]. Departamento de Gastroenterologia, Unidade de Hepatologia, Universidade Federal de São Paulo, São Paulo, SP. [2]. Departamento de Medicina Interna, Universidade Federal do Rio de Janeiro, Rio de Janeiro, RJ.

\begin{abstract}
Introduction: Six genotypes of the hepatitis $\mathrm{C}$ virus (HCV) have been identified thus far, and their distribution is well defined. Genotype 1, which is the most prevalent worldwide, is always compared to genotypes 2 and 3, particularly in terms of treatment response. However, little is known about the differences between genotypes 2 and 3 because these genotypes are analyzed together in most studies. Therefore, the aim of this study was to evaluate differences in the clinical, epidemiological, laboratory, and histological parameters between HCV-2 and HCV-3. Methods: Patients with chronic hepatitis C infected with genotypes 2 and 3 were studied retrospectively and compared according to clinical, laboratory, and histological aspects. Hepatitis $\mathrm{C}$ virusribonucleic acid (HCV-RNA) was analyzed quantitatively by TaqMan ${ }^{\circledR}$ real-time PCR, and the HCV genotype was determined by sequencing the 5 '-untranslated region. Results: A total of 306 patients with chronic HCV-2 (n=50) and HCV-3 $(n=256)$ were studied. Subtype $2 b(n=17 / 50)$ and subtype $3 a(n=244 / 256)$ were the most prevalent among patients infected with $\mathrm{HCV}-2$ and HCV-3, respectively. The mean age was $47 \pm 10$ years, and there was a predominance of men in the group studied (61\%). Comparative analysis between $\mathrm{HCV}-2$ and $\mathrm{HCV}-3$ showed a younger age $(\mathrm{p}=0.002)$, less prevalence of arterial hypertension $(\mathrm{p}=0.03)$, higher serum albumin levels $(\mathrm{p}=0.01)$, more advanced stage of liver fibrosis $(\mathrm{p}=0.03)$, and higher frequency of steatosis in patients with HCV-3 ( $\mathrm{p}=0.001$ ). After multivariate regression analysis, all the variables, except serum albumin, remained as variables associated with HCV-3 in the final model. Conclusions: Clinical and histological differences exist between HCV-2 and HVC-3, which suggests the need for separate analyses of these genotypes.
\end{abstract}

Keywords: Hepatitis C. HCV-2. HCV-3. Fibrosis.

\section{INTRODUCTION}

Hepatitis C affects thousands of people around the world, causes chronic liver disease that can progress to liver cirrhosis, and is a leading cause of liver transplantation. The hepatitis $\mathrm{C}$ virus (HCV) is characterized by genetic heterogeneity, which permits its classification into distinct genotypes and subtypes by phylogenetic analysis ${ }^{1}$. This genetic diversity is related to the origin of the virus, its interesting evolution, its geographic and epidemiological pattern of dissemination, and its long persistence in humans ${ }^{2,3}$. Simmonds et al. ${ }^{1}$ proposed the classification of $\mathrm{HCV}$ into six viral genotypes with several subtypes: 1 (1a, 1b, 1c), 2 (2a, 2b, 2c), 3 (3a, 3b), 4, 5 (5a), and 6. Genotypes $1 \mathrm{a}$ and $1 \mathrm{~b}$ are the most prevalent in western countries $^{1}$, with genotype $1 \mathrm{~b}$ being the most common in

\footnotetext{
Address to: Dr $^{\mathrm{a}}$ Maria Lucia Gomes Ferraz. Dept ${ }^{\underline{0}}$ Gastroenterologia/UNIFESP. Rua Botucatu 740, 04023-900 São Paulo, SP, Brasil.

Phone: 5511 5576-4050; Fax: 5511 5572-9532

e-mail: marialucia.ferraz@uol.com.br

Received 21 January 2014

Accepted 14 April 2014
}

Europe $^{4-6}$ and genotype 1a being the most common in the United States $^{7,8}$. Genotype 2 and its subtypes predominate in western Africa $^{9-11}$. Genotype 3a is the second most common genotype in Europe after genotype $1^{4,6}$. Genotype 4 is prevalent in the Middle East $^{12-14}$ and in Central Africa ${ }^{15-17}$, while genotype 5 is common in South Africa ${ }^{1,18}$, and genotype 6 is found mainly in South Asia ${ }^{19-21}$. Genotype 7 has been found in Vietnamese patients with chronic hepatitis $\mathrm{C}$, although some authors have advocated that it should be reclassified as a subtype of genotype $6^{22}$.

In addition to the wide geographic distribution of $\mathrm{HCV}$ genotypes and subtypes, HCV exhibits a specific pattern of transmission. For example, genotypes $1 \mathrm{a}, 3 \mathrm{a}$, and 4 are associated mainly with intravenous drug use, while genotypes $1 \mathrm{~b}$ and 2 are associated with transmission through blood transfusion $^{23-25}$. With respect to the treatment of chronic hepatitis $\mathrm{C}$, genotype 1 is less responsive to antiviral therapy based on pegylated interferon and ribavirin ${ }^{26}$. In contrast, genotypes 2 and 3 show higher response rates to antiviral treatment, and their treatment duration is shorter compared to that of genotype $1^{27}$.

In most studies, patients infected with genotype 1 are compared to those infected with genotypes 2 and 3 , particularly in terms of treatment response. Moreover, little is known about the differences between genotypes 2 and 3 because these genotypes are usually analyzed together. The aim of the present 
study was to evaluate the distribution of HCV genotypes 2 and 3 and their subtypes as well as to determine differences or similarities in clinical, laboratory, and histopathological parameters between these two genotypes.

\section{METHODS}

Patients with chronic hepatitis C caused by genotypes 2 and 3 who were evaluated between 1994 and 2011 at the Hepatitis Unit of the Department of Gastroenterology, Federal University of São Paulo, were studied retrospectively. The criteria for inclusion in the study were as follows: age of 18 years or older, detection of HCV-RNA, and identification of HCV-2 and HCV-3. Patients who were co-infected with human immunodeficiency virus (HIV) or hepatitis B virus (HBV), organ transplant recipients, patients with end-stage renal disease, and patients with alcohol abuse were excluded from the study. Clinical, laboratory, and histological variables were compared between patients with HCV-2 and HCV-3.

\section{Clinical and laboratory assessment}

The following clinical variables were analyzed: gender, age, parenteral transmission risk factors (transfusion of blood and blood derivatives and/or intravenous drug use), estimated duration of infection in patients with a known parenteral transmission risk factor, body mass index (BMI), diabetes mellitus, and arterial hypertension. Laboratory tests included the measurement of serum levels of aspartate aminotransferase (AST), alanine aminotransferase (ALT), gamma-glutamyltransferase (GGT), alkaline phosphatase (AP), bilirubin, albumin, cholesterol, triglycerides, glucose, platelet count, and prothrombin activity (PA).

\section{Molecular tests}

Qualitative HCV-RNA was detected by PCR using the Amplicor Hepatitis C Virus Test, version 2.0 (Roche Molecular Systems, Branchburg, NJ, USA) with a detection limit of 50IU/ $\mathrm{mL}$. HCV genotyping was performed by amplification followed by hybridization of the HCV 5'-untranslated region (INNo-LiPA HCV II, Innogenetics NV, Belgium)

\section{Histological analysis}

Histological analysis was used to evaluate the activity grade and fibrosis stage according to the METAVIR system. If no liver biopsy was available, the patients were classified as cirrhotic in the case of a suggestive radiological image (reduction in liver size, heterogeneous liver, and increased portal vein caliber) and/or evidence of portal hypertension based on the presence of esophageal varices upon digestive endoscopy. The presence of steatosis with or without steatohepatitis was analyzed, and steatohepatitis was classified according to the nonalcoholic fatty liver disease activity score ${ }^{28}$.

\section{Statistical analysis}

Numerical variables are reported as means and standard deviations, and categorical variables are expressed as absolute and relative frequencies. Analyses of skewness and kurtosis and the Kolmogorov-Smirnov test were used to determine whether continuous variables showed a normal distribution. Categorical variables were compared using the chi-square test and Fisher's exact test, when necessary. Student's $t$-test and the MannWhitney test were applied to compare numerical variables. Logistic regression analysis was performed to identify variables that were independently associated with HCV-3. For all tests, $\mathrm{p}<0.05$ was considered statistically significant. Statistical analysis was performed using Statistical Package for the Social Sciences (SPSS) 20.0 software (SPSS, Chicago, IL, USA).

\section{Ethical considerations}

This study was approved by the Ethics Committee of the Federal University of São Paulo.

\section{RESULTS}

A total of 306 patients with HCV-2 ( $\mathrm{n}=50)$ and HCV-3 $(\mathrm{n}=256)$ were studied, and HCV-3 was more $(84 \%)$ common. Subtype $2 \mathrm{~b}(34 \%)$ was the most prevalent among patients infected with HCV-2 $(\mathrm{n}=50)$. Subtype $3 \mathrm{a}$ was identified in 244 (95\%) of the 256 patients infected with HCV-3.

There was a predominance of men in the group of 306 (61\%) patients, and the mean age was $47 \pm 10$ years. Risk factors for parenteral transmission were identified in $54 \%$ of the patients, with a transfusion risk identified in $37 \%$ of the patients and an intravenous drug use risk identified in $17 \%$ of the patients. The mean estimated duration of infection was $23 \pm 8$ years. Arterial hypertension and diabetes mellitus were observed in $19 \%$ and $11 \%$ of cases, respectively. A BMI $\geq 25 \mathrm{~kg} / \mathrm{m}^{2}$ was a characteristic of $56 \%$ of the patients; of these patients, $35 \%$ were overweight and $21 \%$ were obese. Elevated cholesterol and triglyceride levels were observed in $5 \%$ and $8 \%$ of cases, respectively. These data and the mean ALT, AST, GGT, and AP levels are shown in Table 1.

With respect to histology, an activity grade $\geq 2$ was observed in $62 \%$ of the patients, and a fibrosis stage $>2$ was observed in $32 \%$ of the patients. Hepatic steatosis was present in $72 \%$ of the patients, whereas steatohepatitis was observed in only $3.5 \%$.

A comparative analysis between HCV-2 and HCV-3 showed a younger age $(\mathrm{p}=0.002)$, less prevalence of arterial hypertension $(\mathrm{p}=0.03)$, higher serum albumin levels $(\mathrm{p}=0.01)$, more advanced stage of liver fibrosis $(\mathrm{p}=0.03)$, and higher frequency of steatosis in patients with HCV-3 $(p=0.001)$. In addition, patients infected with $\mathrm{HCV}-3$ tended to present a higher frequency of risk factors for parenteral transmission $(\mathrm{p}=0.06)$ and higher aminotransferase levels (Table 2). A comparison of serum cholesterol and triglyceride levels between genotypes was not possible because these parameters were only altered in a small number of patients.

Age, arterial hypertension, serum albumin levels, liver fibrosis, and steatosis were the variables included in the multivariate logistic regression analysis. The results of the analysis indicated that all the variables, except the serum albumin levels, remained independently associated with HCV-3 (Table 3). 
TABLE 1 - Clinical, laboratory, and histological characteristics of patients with chronic hepatitis $\mathrm{C}$ caused by genotypes 2 and 3 .

\begin{tabular}{|c|c|}
\hline Characteristics & $\begin{array}{c}\text { Total } \\
(\mathrm{n}=306)\end{array}$ \\
\hline Age (years)* & $48 \pm 10$ \\
\hline \multicolumn{2}{|l|}{ Gender $(\%)$} \\
\hline male & 61.0 \\
\hline female & 39.0 \\
\hline \multicolumn{2}{|l|}{ Parenteral transmission risk n (\%) } \\
\hline blood transfusion & $106 \quad 36.0$ \\
\hline intravenous drug use & $51 \quad 18.0$ \\
\hline Duration of infection (years)* & $23 \pm 8.3$ \\
\hline Diabetes mellitus & 11.0 \\
\hline Arterial hypertension & 19.0 \\
\hline $\mathrm{BMI} \geq 25 \mathrm{~kg} / \mathrm{m}^{2}$ & 56.0 \\
\hline $\operatorname{AST}(x U L N) *$ & $1.9 \pm 1.5$ \\
\hline $\operatorname{ALT}(\mathrm{xULN})^{*}$ & $2.5 \pm 1.9$ \\
\hline Alkaline phosphatase $(\mathrm{xULN}) *$ & $0.6 \pm 0.7$ \\
\hline GGT (xULN)* & $2.1 \pm 2.1$ \\
\hline Bilirubin (mg/dL)* & $0.93 \pm 0.84$ \\
\hline Prothrombin activity $(\%)^{*}$ & $90.6 \pm 13$ \\
\hline Albumin $(\mathrm{g} / \mathrm{dL})^{*}$ & $4.2 \pm 0.5$ \\
\hline Platelets $\left(\mathrm{n} / \mathrm{mm}^{3}\right)^{*}$ & $183,843 \pm 66,575$ \\
\hline Cholesterol $\geq 200 / \mathrm{dL}$ & 5.0 \\
\hline Triglycerides $\geq 150 \mathrm{mg} / \mathrm{dL}$ & 8.0 \\
\hline \multicolumn{2}{|l|}{ Fibrosis (\%) } \\
\hline $0-2$ & 68.0 \\
\hline $3-4$ & 32.0 \\
\hline cirrhosis & 21.0 \\
\hline \multicolumn{2}{|l|}{ Activity grade $(\%)$} \\
\hline $0-1$ & 38.0 \\
\hline $2-3$ & 62.0 \\
\hline Hepatic steatosis $(\%)$ & 72.0 \\
\hline \multicolumn{2}{|l|}{ Genotype $(\%)$} \\
\hline $2 / 2 \mathrm{a} / 2 \mathrm{~b} / 2 \mathrm{c} / 2 \mathrm{a}, \mathrm{c}$ & $3.0 / 4.0 / 6.0 / 1.0 / 2.0$ \\
\hline $3 a$ & 84.0 \\
\hline
\end{tabular}

BMI: body mass index; AST: aspartate aminotransferase; ALT: alanine aminotransferase; GGT: gamma-glutamyltransferase; ULN: upper limit of normal. *Values are expressed as the mean \pm standard deviation. Histological analysis was performed according to the METAVIR system.

\section{DIscussion}

The distribution of HCV genotypes 2 and 3 and their subtypes varies according to geographic region. In the present study, which evaluated different aspects of HVC-2 and HVC-3, genotype 3 was more prevalent ( $84 \%$ of cases), whereas genotype 2 was identified in only $16 \%$ of cases. Genotypes $3 \mathrm{a}, 2 \mathrm{a}$, and $2 \mathrm{~b}$ were the most common subtypes.

Studies conducted in Brazil have shown a predominance of genotype 3 over genotype 2 among non-genotype-1 patients in all regions of the country. Campiotto et al. ${ }^{29}$ studied the distribution of $\mathrm{HCV}$ genotypes and serotypes in different regions of Brazil and found genotype 3 in $30 \%$ of cases, whereas genotype 2 was identified in only $4.6 \%$ of the subjects.

An investigation of the demographic and epidemiological differences between patients infected with HVC-2 and HVC-3 showed that patients with $\mathrm{HCV}-2$ had a higher mean age. In addition, parenteral transmission of the virus tended to be more frequent among subjects with HCV-3. From an epidemiological point of view, these findings appear to be related because genotype 3 is strongly associated with intravenous drug use, which is more frequent among young individuals. Katsoulidou et al. ${ }^{30}$ studied 1,686 patients with chronic HCV in Greece and mainly identified genotype 3 among patients who contracted the infection through the use of intravenous drugs (58\%). Taken together, these results suggest that genotype 3 was recently introduced in the population ${ }^{3}$. In fact, HCV genotype incidence data have shown a 1.5 -fold reduction in the prevalence of genotype 2 between 1970 and 1990 and a 13 -fold increase in that of genotype 3 over the same period ${ }^{30}$.

The evaluation of clinical and laboratory differences between HVC-2 and HVC-3 showed that arterial hypertension was more frequent among patients with HCV-2. This finding might be due to the older age of these patients, as arterial hypertension is more frequent among older subjects. The laboratory parameters, with the exception of albumin, were similar for the two genotypes. Although the albumin levels were approximately normal in patients with HCV-3, they were slightly higher compared to those in patients with HCV-2. Despite this mathematical difference, this finding appears to be irrelevant from a clinical point of view.

Hepatic steatosis and advanced fibrosis were more frequent among patients infected with HCV-3 compared to patients with HCV-2. Studies have demonstrated a higher prevalence of steatosis in patients infected with genotype 3 compared to patients infected with other genotypes ${ }^{31}$. Rubbia-Brandt et al. ${ }^{32}$ studied 101 patients with chronic hepatitis $\mathrm{C}$, excluding patients with risk factors for nonalcoholic fatty liver disease, and they observed hepatic steatosis in $41 \%$ of the patients, irrespective of gender, age, or source of infection. Genotype 3 was more frequent than the other genotypes. The physiopathological mechanisms underlying the higher frequency of hepatic steatosis in patients with hepatitis $C$ and genotype 3 suggest that the virus may have a cytopathic effect. According to Barba et al. ${ }^{33}$, hepatic steatosis in hepatitis $\mathrm{C}$ appears to be the result of interference with the expression of genes involved in lipid metabolism. 
TABLE 2 - Comparative analysis of clinical, laboratory, and histological variables in 306 patients with chronic hepatitis C genotypes 2 and 3.

\begin{tabular}{|c|c|c|c|}
\hline Characteristics & $\begin{array}{c}\text { Genotype } 2 \\
(\mathrm{n}=50)\end{array}$ & $\begin{array}{c}\text { Genotype } 3 \\
(\mathrm{n}=256)\end{array}$ & $\mathrm{p}$ value \\
\hline Age (years) $)^{\mathrm{a}}$ & $52 \pm 9$ & $47 \pm 10$ & 0.002 \\
\hline Parenteral transmission risk* & 42 & 56 & 0.06 \\
\hline Duration of infection (years) ${ }^{\mathrm{a}}$ & $21 \pm 9$ & $24 \pm 7$ & 0.2 \\
\hline Arterial hypertension* & 30 & 17 & 0.03 \\
\hline $\mathrm{BMI} \geq 25 \mathrm{~kg} / \mathrm{m}^{2}$, yes $/ \mathrm{no}^{*}$ & $17 / 18$ & $83 / 82$ & 0.7 \\
\hline $\operatorname{AST}(x U L N)^{a}$ & $1.6 \pm 1.4$ & $2.0 \pm 1.5$ & 0.07 \\
\hline $\operatorname{ALT}(x U L N)^{a}$ & $2.0 \pm 1.8$ & $2.6 \pm 2.1$ & 0.06 \\
\hline Bilirubin $(\mathrm{mg} / \mathrm{dL})^{\mathrm{a}}$ & $1 \pm 1.7$ & $0.9 \pm 0.5$ & 0.2 \\
\hline Prothrombin activity ${ }^{\mathrm{a}}$ & $88 \pm 17$ & $91 \pm 12$ & 0.16 \\
\hline $\operatorname{Albumin}(\mathrm{g} / \mathrm{dL})^{\mathrm{a}}$ & $4 \pm 0.4$ & $4.2 \pm 0.4$ & 0.01 \\
\hline Platelets $\left(\mathrm{n} / \mathrm{mm}^{3}\right)^{\mathrm{a}}$ & $187,200 \pm 60,427$ & $180,977 \pm 67,587$ & 0.5 \\
\hline Fibrosis, $0-2 / 3-4^{*}$ & $81 / 19$ & $65 / 35$ & 0.03 \\
\hline Activity grade, $0-1 / 2-3^{*}$ & $64 / 36$ & $53 / 47$ & 0.1 \\
\hline Hepatic steatosis, yes/no* & $49 / 51$ & $75 / 25$ & 0.001 \\
\hline
\end{tabular}

BMI: body mass index; AST: aspartate aminotransferase; ALT: alanine aminotransferase; GGT: gamma-glutamyltransferase; ULN: upper limit of normal. *Numbers are expressed as percentages. Data analysis was performed using the chi-square test, Student's $t$-test and Mann-Whitney test. ${ }^{a}$ Mean \pm SD. Histological analysis was performed according to the METAVIR system.

TABLE 3 - Final model illustrating multivariate logistic regression analysis of variables associated with HCV-3.

\begin{tabular}{|c|c|c|c|c|}
\hline Characteristics & $\mathrm{p}$ value & OR & \multicolumn{2}{|c|}{$95 \% \mathrm{CI}$} \\
\hline Age (younger) & 0.007 & 0.94 & 0.905 & 0.984 \\
\hline Arterial hypertension (less frequent) & 0.03 & 0.37 & 0.145 & 0.943 \\
\hline Albumin (g/dL) & 0.05 & 2.41 & 0.995 & 5.879 \\
\hline
\end{tabular}

HCV: hepatitis C virus; OR: odds ratio; 95\%CI: 95\% confidence interval.

Another finding of the present study was the association between HCV-3 and more advanced stages of fibrosis. Several risk factors have been associated with the histological progression of chronic hepatitis $\mathrm{C}$, such as the duration of infection, age at infection, body weight, alcohol consumption, and double infection with HBV or HIV. However, the contribution of the HCV genotype to the progression of liver fibrosis is unclear. Bochud et al. ${ }^{34}$ estimated the progression rate of fibrosis (METAVIR score/time of infection in years) in 1,189 patients and found a significant association between genotype 3 and advanced liver fibrosis. Genotype 3 was identified as an independent risk factor for fibrosis progression $(\mathrm{OR}=1.89,95 \% \mathrm{CI}: 1.37-2.61, \mathrm{p}<0.001)$, as individuals with this genotype presented a higher progression rate compared to individuals with the other genotypes. In a systematic review of the literature conducted by Prosbt et al. ${ }^{35}$, genotype 3 was associated with more rapid progression of liver fibrosis. 
Possible explanations for the more advanced fibrosis in patients with genotype 3 include the presence of other factors associated with fibrosis progression, such as excessive alcohol consumption, greater pathogenicity of this genotype in terms of its ability to induce liver fibrosis, and the association with hepatic steatosis. Because alcohol abuse was excluded from the present study, this factor is not likely to explain the finding of more advanced fibrosis in this group of patients. It is therefore likely that characteristics of the genotype 3 itself, or the association of this genotype with steatosis are responsible for this finding. In this respect, studies have suggested that hepatic steatosis is associated with fibrosis progression in patients infected with genotype 3 . Westin et al. ${ }^{36}$ studied 98 patients with genotype $3(n=25)$ and non-genotype $3(n=64) \mathrm{HCV}$ who were submitted to two liver biopsies and observed that the prevalence and degree of steatosis were strongly associated with genotype 3 , irrespective of gender, age, BMI, and alcohol consumption. Faster fibrosis progression was more prevalent in patients with hepatic steatosis, an effect that was observed mainly in patients infected with genotype 3 .

It can be concluded that differences exist between HVC-2 and HVC-3. Patients infected with HCV-3 were younger and had less frequent arterial hypertension; additionally, the prevalence of advanced liver fibrosis and hepatic steatosis was higher in these patients when compared to patients infected with HCV2 . These differences suggest that genotypes 2 and 3 should be analyzed separately, as they are genotypes with different clinical and histopathological characteristics.

\section{CONFLICT OF INTEREST}

The authors declare that there is no conflict of interest.

\section{REFERENCES}

1. Simmonds P, Bukh J, Combet C, Deleage G, Enomoto N, Feinstone S, et al. Consensus proposals for a unified system of nomenclature of hepatitis C virus genotypes. Hepatology 2005; 42:962-973.

2. Raghwani J, Thomas XV, Koekkoek SM, Schinkel J, Molenkamp R, van de Laar TJ, et al. Origin and evolution of the unique hepatitis $\mathrm{C}$ virus circulating recombinant form 2k/1b. J Virol 2012; 86:2212-2220.

3. Simmonds P. The origin and evolution of hepatitis viruses in humans. J Gen Virol 2001; 82:693-712.

4. Simmonds P, Mellor J, Craxi A, Sanchez-Tapias JM, Alberti A, Prieto J, et al. Epidemiological, clinical and therapeutic associations of hepatitis $\mathrm{C}$ types in western European patients. J Hepatol 1996; 24:517-524.

5. Nousbaum JB, Pol S, Nalpas B, Landais P, Berthelot P, Brechot C. Hepatitis $C$ virus type $1 \mathrm{~b}(2)$ infection in France and Italy. Collaborative Study Group. Ann Intern Med 1995; 122:161-168.

6. Esteban JI, Sauleda S, Quer J. The changing epidemiology of hepatitis C virus infection in Europe. J Hepatol 2008; 48:148-162.

7. Zein NN, Rakela J, Krawitt EL, Reddy KR, Tominaga T, Persing DH. Hepatitis C virus genotypes in the United States: epidemiology, pathogenicity, and response to interferon therapy. Collaborative Study Group. Ann Intern Med 1996; 125:634-639.

8. Nainan OV, Alter MJ, Kruszon-Moran D, Gao FX, Xia G, McQuillan G, et al. Hepatitis $\mathrm{C}$ virus genotypes and viral concentrations in participants of a general population survey in the United States. Gastroenterology 2006; 131:478-484.

9. Jeannel D, Fretz C, Traore Y, Kohdjo N, Bigot A, Pe Gamy E, et al. Evidence for high genetic diversity and long-term endemicity of hepatitis C virus genotypes 1 and 2 in West Africa. J Med Virol 1998; 55:92-97.

10. Ruggieri A, Argentini C, Kouruma F, Chionne P, D'Ugo E, Spada E, et al. Heterogeneity of hepatitis $\mathrm{C}$ virus genotype 2 variants in West Central Africa (Guinea Conakry). J Gen Virol 1996; 77:2073-2076.

11. Candotti D, Temple J, Sarkodie F, Allain JP. Frequent recovery and broad genotype 2 diversity characterize hepatitis $\mathrm{C}$ virus infection in Ghana, West Africa. J Virol 2003; 77:7914-7923.

12. Chamberlain RW, Adams N, Saeed AA, Simmonds P, Elliott RM. Complete nucleotide sequence of a type 4 hepatitis $\mathrm{C}$ virus variant, the predominant genotype in the Middle East. J Gen Virol 1997; 78:13411347.

13. Abdel-Moneim AS, Bamaga MS, Shehab GM, Abu-Elsaad AA, Farahat FM. HCV infection among Saudi population: high prevalence of genotype 4 and increased viral clearance rate. PLoS One 2012; 7:e29781.

14. Osoba AO, Ibrahim M, Abdelaal MA, Al-Mowallad A, Al Shareef B, Hussein BA. Hepatitis $C$ virus genotyping by polymerase chain reaction and DNA enzyme immunoassay among Saudi patients in the Western Province, Saudi Arabia. Ann Saudi Med 2000; 20:394-397.

15. Xu LZ, Larzul D, Delaporte E, Brechot C, Kremsdorf D. Hepatitis C virus genotype 4 is highly prevalent in central Africa (Gabon). J Gen Virol 1994; 75:2393-2398.

16. Njouom R, Caron M, Besson G, Njouom-Atome GR, Makuwa M, Pouillot R, et al. Phylogeography, risk factors and genetic history of hepatitis $\mathrm{C}$ virus in Gabon, central Africa. PLoS One 2012; 7:e42002.

17. Njouom R, Frost E, Deslandes S, Mamadou-Yaya F, Labbé AC, Pouillot R, et al. Predominance of hepatitis $\mathrm{C}$ virus genotype 4 infection and rapid transmission between 1935 and 1965 in the Central African Republic. J Gen Virol 2009; 90:2452-2456.

18. Chamberlain RW, Adams NJ, Taylor LA, Simmonds P, Elliott RM. The complete coding sequence of hepatitis $\mathrm{C}$ virus genotype $5 \mathrm{a}$, the predominant genotype in South Africa. Biochem Biophys Res Commun 1997; 236:44-49.

19. Wong DA, Tong LK, Lim W. High prevalence of hepatitis C virus genotype 6 among certain risk groups in Hong Kong. Eur J Epidemiol $1998 ; 14: 421-426$.

20. Pham VH, Nguyen HD, Ho PT, Banh DV, Pham HL, Pham PH, et al. Very high prevalence of hepatitis $\mathrm{C}$ virus genotype 6 variants in southern Vietnam: large-scale survey based on sequence determination. Jpn J Infect Dis 2011; 64:537-539.

21. Simmonds P, Mellor J, Sakuldamrongpanich T, Nuchaprayoon C, Tanprasert S, Holmes EC, et al. Evolutionary analysis of variants of hepatitis $\mathrm{C}$ virus found in South-East Asia: comparison with classifications based upon sequence similarity. J Gen Virol 1996; 77:3013-3024.

22. Nguyen MH, Keeffe EB. Chronic hepatitis C: genotypes 4 to 9. Clin Liver Dis 2005; 9:411-426.

23. Kabir A, Alavian SM, Keyvani H. Distribution of hepatitis $\mathrm{C}$ virus genotypes in patients infected by different sources and its correlation with clinical and virological parameters: a preliminary study. Comp Hepatol 2006; 5:4.

24. Basaras M, Lombera N, de las Heras B, Lopez C, Arrese E, Cisterna R. Distribution of HCV genotypes in patients infected by different sources. Res Virol 1997; 148:367-373.

25. Pawlotsky JM, Tsakiris L, Roudot-Thoraval F, Pellet C, Stuyver L, Duval J, et al. Relationship between hepatitis $\mathrm{C}$ virus genotypes and sources of infection in patients with chronic hepatitis C. J Infect Dis 1995; 171:16071610.

26. Fried MW, Shiffman ML, Reddy KR, Smith C, Marinos G, Goncales Jr FL, et al. Peginterferon alfa-2a plus ribavirin for chronic hepatitis $\mathrm{C}$ virus infection. N Engl J Med 2002; 347:975-982. 
27. Manns MP, McHutchison JG, Gordon SC, Rustgi VK, Shiffman M, Reindollar R, et al. Peginterferon alfa-2b plus ribavirin compared with interferon alfa-2b plus ribavirin for initial treatment of chronic hepatitis C: a randomised trial. Lancet 2001; 358:958-965.

28. Kleiner DE, Brunt EM, Van Natta M, Behling C, Contos MJ, Cummings OW, et al. Design and validation of a histological scoring system for nonalcoholic fatty liver disease. Hepatology 2005; 41:1313-1321.

29. Campiotto S, Pinho JR, Carrilho FJ, Silva LC, Souto FJ, Spinelli V, et al. Geographic distribution of hepatitis $\mathrm{C}$ virus genotypes in Brazil. Braz J Med Biol Res 2005; 38:41-49.

30. Katsoulidou A, Sypsa V, Tassopoulos NC, Boletis J, Karafoulidou A, Ketikoglou I, et al. Molecular epidemiology of hepatitis C virus (HCV) in Greece: temporal trends in HCV genotype-specific incidence and molecular characterization of genotype 4 isolates. J Viral Hepat 2006; 13:19-27.

31. Matos CA, Perez RM, Pacheco MS, Figueiredo-Mendes CG, Lopes-Neto E, Oliveira Jr EB, et al. Steatosis in chronic hepatitis C: relationship to the virus and host risk factors. J Gastroenterol Hepatol 2006; 21:1236-1239.
32. Rubbia-Brandt L, Quadri R, Abid K, Giostra E, Male PJ, Mentha G, et al. Hepatocyte steatosis is a cytopathic effect of hepatitis $\mathrm{C}$ virus genotype 3 . J Hepatol 2000; 33:106-115.

33. Barba G, Harper F, Harada T, Kohara M, Goulinet S, Matsuura Y, et al. Hepatitis $\mathrm{C}$ virus core protein shows a cytoplasmic localization and associates to cellular lipid storage droplets. Proc Natl Acad Sci USA 1997; 94:1200-1205.

34. Bochud PY, Cai T, Overbeck K, Bochud M, Dufour JF, Mullhaupt B, et al. Genotype 3 is associated with accelerated fibrosis progression in chronic hepatitis C. J Hepatol 2009; 51:655-666.

35. Probst A, Dang T, Bochud M, Egger M, Negro F, Bochud PY. Role of hepatitis $\mathrm{C}$ virus genotype 3 in liver fibrosis progression--a systematic review and meta-analysis. J Viral Hepat 2011; 18:745-759.

36. Westin J, Nordlinder H, Lagging M, Norkrans G, Wejstal R. Steatosis accelerates fibrosis development over time in hepatitis $\mathrm{C}$ virus genotype 3 infected patients. J Hepatol 2002; 37:837-842. 